\title{
Investigation of the vitamin B12 deficiency with peripheral neuropathy in patients with type 2 diabetes mellitus treated using metformin
}

\author{
Serdar Olt, Orhan Oznas \\ Department of Internal Medicine Adıyaman University Medical Faculty, Adıyaman, Turkey
}

\begin{abstract}
OBJECTIVE: The relationship between vitamin B12 deficiency and peripheral neuropathy has been shown in a number of previous studies. Metformin is the indispensable first-line treatment for type 2 diabetes mellitus (DM) worldwide. One of the adverse effects of the use of metformin is vitamin B12 deficiency. In the present study, we investigated the relationship between vitamin B12 deficiency and peripheral neuropathy due to the use of metformin.
\end{abstract}

METHODS: Patient's laboratory and electromyography (EMG) data were retrospectively reviewed. Patients with no EMG report and other necessary information were excluded from the study.

RESULTS: Eighty-six patients with type 2 DM using metformin were included in the study. Of these patients, 26 were males and 60 were females. The mean age of the patients was $55.1 \pm 7.7$ years. The mean body mass index of the patients was $29.1 \pm 9.01 \mathrm{~kg} / \mathrm{m}^{2}$. The mean $\mathrm{HbA1c}$ level of the patients was $8.6 \% \pm 2.1 \%$. The mean duration of diabetes was $8.02 \pm 5.4$ years. The incidence of vitamin B12 deficiency was $38.4 \%$. Peripheral neuropathy was detected in $33.7 \%$ patients. There was no statistically significant difference in vitamin B12 levels between patients with peripheral neuropathy and those without peripheral neuropathy $(p=0.64)$.

CONCLUSION: Therefore, it can be concluded that the lack of vitamin B12 secondary to the use of metformin did not significantly increase the frequency of peripheral neuropathy.

Keywords: Metformin; peripheral neuropathy; type 2 diabetes mellitus; vitamin b12.

$\mathrm{M}$ etformin is the indispensable first-line treatment for type 2 diabetes mellitus (DM) worldwide. It prevents the absorption of vitamin B12 in the ileum. It is believed that this mechanism is caused by inhibition of calcium dependent channels in the ileum. It is known that prolonged use of metformin causes vitamin B12 deficiency by this mechanism [1-5]. Vitamin B12 deficiency may lead to neuropsychiatric and hematological abnormalities. The relationship between vitamin B12 deficiency and peripheral neuropathy has been shown in previous studies [6-7]. 
Herein, we investigated the relationship between vitamin B12 deficiency due to the use of metformin and peripheral neuropathy.

\section{MATERIALS AND METHODS}

Eighty-six patients with type 2 DM aged $>18$ years who were using metformin were included in the study. The patients' files were retrospectively reviewed. Vitamin B12 levels, age, sex, duration of diabetes, $\mathrm{HbA} 1 \mathrm{c}$ levels, and body mass index data were recorded from the archives of the Adryaman Medical Faculty Hospital. The presence of peripheral neuropathy was determined by electromyography (EMG). Patients with no EMG report and other information were excluded from the study.

All analyses were performed using the SPSS for Windows (version 21.0; SPSS/IBM, Chicago, IL). Descriptive statistics and Mann-Whitney $U$ tests were used when appropriate. The statistical significance level was accepted as a $\mathrm{P}$ value of $<0.05$.

\section{RESULTS}

Twenty-six of the patients were males and 60 were females. The mean age of the patients was $55.1 \pm 7.7$ years. The mean body mass index of the patients was $29.1 \pm 9.01 \mathrm{~kg} / \mathrm{m}^{2}$. The mean HbA1c level of the patients was $8.6 \% \pm 2.1 \%$. The mean duration of diabetes was $8.02 \pm 5.4$ years.

The incidence of vitamin B12 deficiency in the patients was $38.4 \%$. Peripheral neuropathy was detected in 29 of the patients (33.7\%). The general characteristics of the patients and the laboratory values are summarized in Table 1.

There was no statistically significant differences vitamin B12 levels between patients with peripheral neuropathy and those without peripheral neuropathy $(p=0.64)$. The relationship between peripheral neuropathy and vitamin B12 is shown in Table 2 and Figure 1.

\section{DISCUSSION}

Metformin is the first and most important treatment for type $2 \mathrm{DM}$ worldwide if there is no contraindication. Metformin leads the insulin sensitizing effect on the liver. Although gastrointestinal side effects are most common because of the use of metformin, it can also lead to serious side effects, such as lactic acidosis and vitamin B12 deficiency [8-9].

In a study by Ko et al., the incidence of vitamin B12 deficiency was increased in patients who have been treated with metformin for $\geq 4$ years and those who have been using high-dose metformin [3].

Vitamin B12 deficiency can lead to clinically significant but treatable conditions. These include a wide range of clinical conditions, such as memory impairment, peripheral neuropathy, dementia, delirium, subacute combined degeneration of the spinal cord, megaloblastic anemia and pancytopenia.

TABLE 1. Demographic and clinical features of patients

\begin{tabular}{lc} 
Parameters & $\mathrm{n}(\%)$ or Mean \pm SD \\
\hline Age & $55.1 \pm 7.7$ \\
Gender (M/F) (\%) & $26(30.2) / 60(69.8)$ \\
HbA1c (\%) & $8.6 \pm 2.1$ \\
DM duration (years) & $8.02 \pm 5.4$ \\
Body Mass Index $\left(\mathrm{kg} / \mathrm{m}^{2}\right)$ & $29.1 \pm 9.01$ \\
Vitamin B12 deficiency frequency (\%) & $33(38.4)$ \\
Neuropathy frequency $(\%)$ & $29(33.7)$
\end{tabular}

TABLE 2. Comparison of vitamin B12 levels between the groups

Parameters

Neuropathy-positive group

Mean of Rank
Neuropathy-negative group

Mean of Rank 


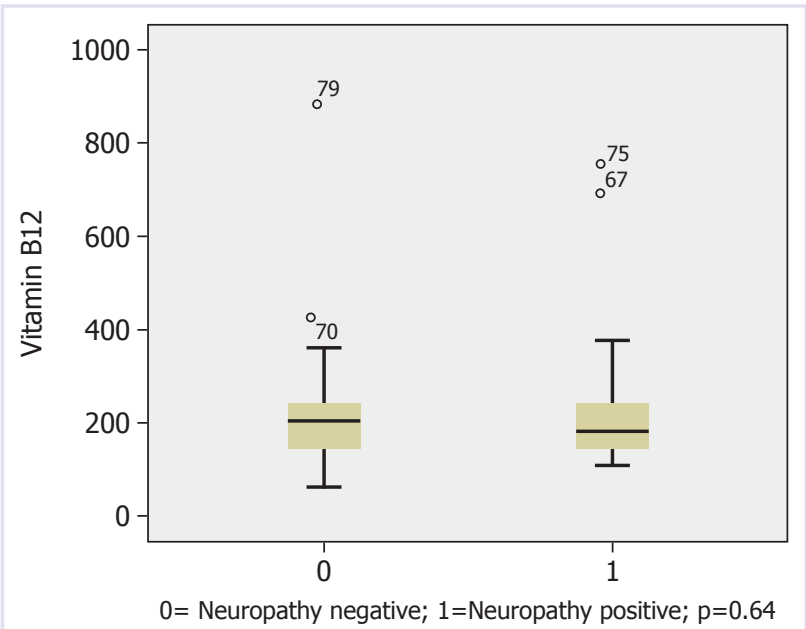

FIGURE 1. Graphic of vitamin B12 levels between the groups.

Studies investigating the relationship between peripheral neuropathy and vitamin B12 deficiency have contradictory results. In a study by Ahmed et al, no significant relationship was found between vitamin B12 vitality deficiency and peripheral neuropathy because of the use of metformin [10]. Contrary to the results of above study, a study by Singh et al. reported that the use of metformin was significantly associated with vitamin B12 deficiency and peripheral neuropathy [11]. In a study conducted by Jayabalan et al, vitamin B12 supplementation in patients with diabetic peripheral neuropathy was found to have no effect on healing [12].

In our study, there was no statistically significant difference in vitamin B12 levels between patients with peripheral neuropathy and those without peripheral neuropathy $(\mathrm{p}=0.64)$.

In a study conducted by Raizada et al,, no significant increase in the prevalence of neuropathy was found in vitamin B12-deficient patients compared with patients with normal vitamin B12 levels. They emphasized that the increased the duration of diabetes was associated with the severity of vitamin B12 deficiency [13].

In a letter by Chowta and Tiwary that commented on an article, they emphasized that exhaustion of vitamin B12 stores usually occurs after 12-15 years of absolute vitamin B12 deficiency. Thus, the duration of diabetes is the most crucial point in the development of vitamin B12 associated neuropathy. In our study, the mean diabetes duration was $8.02 \pm 5.4$ years. Therefore, in future studies, we and other researchers should include a population with longer diabetes duration to further illuminate this point [14].

In conclusion, it can be said that deficiency of vitamin B12 secondary to the use of metformin in the Adiyaman province does not obviously increase the frequency of peripheral neuropathy.

Finally, this present study had some limitations. These were the small number of patients and the retrospective nature of the study. This issue will be better illuminated in the future by prospective studies with a large number of patients.

Conflict of Interest: No conflict of interest was declared by the authors.

Financial Disclosure: The authors declared that this study has received no financial support.

Authorship contributions: Concept - S.O.; Design - S.O.; Supervision - S.O.; Materials - S.O., O.O.; Data collection \&/or processing - S.O., O.O.; Analysis and/or interpretation - S.O.; Literature search - S.O.; Writing - S.O.; Critical review - S.O.

\section{REFERENCES}

1. Chapman LE, Darling AL, Brown JE. Association between metformin and vitamin $B(12)$ deficiency in patients with type 2 diabetes: A systematic review and meta-analysis. Diabetes Metab 2016;42:316-27. [CrossRef]

2. Iftikhar R, Kamran SM, Qadir A, Iqbal Z, bin Usman H. Prevalence of vitamin B12 deficiency in patients of type 2 diabetes mellitus on metformin: a case control study from Pakistan. Pan Afr Med J 2013;16:67. [CrossRef]

3. Ko SH, Ko SH, Ahn YB, Song KH, Han KD, Park YM, et al. Association of vitamin B12 deficiency and metformin use in patients with type 2 diabetes. J Korean Med Sci 2014;29:965-72.

4. Mazokopakis EE, Starakis IK. Recommendations for diagnosis and management of metformin-induced vitamin B12 (Cbl) deficiency. Diabetes Res Clin Pract 2012;97:359-67. [CrossRef]

5. Kumthekar AA, Gidwani HV, Kumthekar AB. Metformin associated B12 deficiency. J Assoc Physicians India 2012;60:58-60.

6. Roy RP, Ghosh K, Ghosh M, Acharyya A, Bhattacharya A, Pal M, Chakraborty S, Sengupta N. Study of Vitamin B(12) deficiency and peripheral neuropathy in metformin-treated early Type 2 diabetes mellitus. Indian J Endocrinol Metab 2016;20:631-7. [CrossRef] 
7. Ekabe CJ, Kehbila J, Abanda MH, Kadia BM, Sama CB, Monekosso GL. Vitamin B12 deficiency neuropathy; a rare diagnosis in young adults: a case report. BMC Res Notes 2017;10:72.

8. Houwerzijl EJ, Snoek WJ, van Haastert M, Holman ND. Severe lactic acidosis due to metformin therapy in a patient with contra-indications for metformin. Ned Tijdschr Geneeskd 2000;144:1923-6.

9. Niafar M, Hai F, Porhomayon J, Nader ND. The role of metformin on vitamin B12 deficiency: a meta-analysis review. Intern Emerg Med 2015;10:93-102. [CrossRef]

10. Ahmed MA, Muntingh G, Rheeder P. Vitamin B12 deficiency in metformin-treated type-2 diabetes patients, prevalence and association with peripheral neuropathy. BMC Pharmacol Toxicol
2016;17:44. [CrossRef]

11. Singh AK, Kumar A, Karmakar D, Jha RK. Association of B12 deficiency and clinical neuropathy with metformin use in type 2 diabetes patients. J Postgrad Med 2013;59:253-7. [CrossRef]

12. Jayabalan B, Low LL. Vitamin B supplementation for diabetic peripheral neuropathy. Singapore Med J 2016;57:55-9. [CrossRef]

13. Raizada N, Jyotsna VP, Sreenivas V, Tandon N. Serum Vitamin B12 Levels in Type 2 Diabetes Patients on Metformin Compared to those Never on Metformin: A Cross-sectional Study. Indian J Endocrinol Metab 2017;21:424-8. [CrossRef]

14. Chowta MN, Tiwary G. Comment on: association of B12 deficiency and clinical neuropathy with metformin use in type 2 diabetes patients. J Postgrad Med 2014;60:96-7. 